\title{
Production of Bioethanol from Bamboo using Thermotolerant Yeast with Simultaneous Saccharification and Fermentation Process
}

\author{
Sasikala Ganesan* and N.O. Gopal \\ PGP College of Agricultural Sciences, Namakkal, India \\ *Corresponding author
}

\section{A B S T R A C T}

\section{Keywords}

Bioethanol,

Bamboo,

Simultaneous

saccharification and

Fermentation (SSF)

Process and

Thermotolerant

yeast

Article Info

Accepted:

15 February 2019

Available Online:

10 March 2019
Bioethanol from lignocellulosic substrates could be a key alternative and sustainable fuel because of diminishing fossil fuel reserves and increased concerns over environmental pollution. Therefore, recent focus has made on cheaply available lignocellulosic substrate like bamboo. Production of bioethanol using bamboo as feedstock is gaining importance as of relatively higher growth rate and their abundant and sustainable availability in the tropics. In this study, a perennial woody grass bamboo was exploited for the production of bioethanol using the simultaneous saccharification and fermentation process with cellulase enzyme and a thermotolerant yeast Kluyveromyces marxianus TY16 for efficient conversion. The bamboo was found to contain maximum cellulose content of $49.30 \%$. SEM and FTIR analysis of the acid treated and untreated substrate showed the difference in the structural changes. Under the optimum conditions of SSF, maximum ethanol concentration of $26.04 \mathrm{gl}^{-1}$ was achieved from the bamboo substrate. Thus, it showed that the bamboo biomass conversion using the SSF process has the good potential for ethanol production industries.

\section{Introduction}

Global increase in energy consumption, depletion of fossil fuel reserves and concerns about climate change urge us to explore renewable and ecofriendly sources of energy. Bioethanol derived from lignocellulosic plant biomass is gaining more importance because they are abundant, inexpensive and renewable and it does not cause any threat to national food security. Among the different biomass, bamboo is one of the cellulosic alternative, offers the most promising source for alternative fuel. It uses less resources and no harm to environment.

Bamboo, a perennial woody grass belongs to the Family Gramineae. It is widely distributed in many countries in Asia, with an annual production of 6-7 million tonnes. It produces $800 \%$ more gallons of ethanol per acre than corn. Its biomass is accumulating daily, but little of them have been used especially edible bamboo shoots and most of them are wasted 
without utilizing. Its accumulation is about 26.1 tonnes per ha, with annual growth around 13.84 tonnes per ha under 5 year rotation cutting. They are the highest biomass producers among other bioenergy plants in terms of tonnes of dry weight per acre per year. In addition, existing systems for bamboo plantation, harvesting and transportation would provide advantageous opportunities to build bamboo based refineries as compared to other potential bioenergy plants such as switch grass and miscanthus ${ }^{1}$. It is also the key biomass material for the balance of oxygen and carbon dioxide in the atmosphere. Its $\mathrm{CO}_{2}$ storage rate per unit area of plantation is four times that of hardwood and the release of oxygen is $35 \%$ higher than that of trees ${ }^{2}$. Because of advantages such as fast growth, high cellulose content, low lignin content and abundant availability, it has the potential to become one of the most widely used bioenergy resource ${ }^{3}$.

The basic processes in production of bioethanol from lignocellulosic biomass are (1) pre-treatment, which renders cellulose and hemicellulose more accessible to the subsequent steps; (2) acid or enzymatic hydrolysis to break down polysaccharides to simple sugars; (3) fermentation of the sugars (hexoses and pentoses) to ethanol using microorganisms; (4) separation and concentration of ethanol by distillation. The enzymatic hydrolysis and fermentation process can be accomplished using the different strategies viz., Separate Hydrolysis and Fermentation (SHF) and Simultaneous Saccharification and Fermentation (SSF). In SHF, hydrolysis and fermentation are carried out in separate vessels under their own optimal conditions which is associated with end-product inhibition of enzyme activity and contamination problems. In order to eliminate the drawbacks of SHF process, SSF has been developed that combines hydrolysis and fermentation in one vessel. Sugars produced during hydrolysis are immediately fermented into ethanol and thus, problems associated with sugar accumulation and enzyme inhibition as well as contamination can be avoided $^{4}$. Another advantage is the cost reduction resulting from the use of only one reactor. One of the major drawbacks of the SSF from biomass is the different optimum temperatures for saccharification and fermentation processes. The solution to this disjunctive is the utilization of thermotolerant yeasts capable of fermenting glucose to ethanol at temperatures above $40^{\circ} \mathrm{C}$, which are closer to the optima for the activity of the cellulolytic complex in the range of $35^{\circ} \mathrm{C}$ to $45^{\circ} \mathrm{C}$ during saccharification ${ }^{5}$ and 6 . Thermotolerant yeasts can be obtained by selecting survivors after a shock process at relatively high temperatures. Thus, it is observed that the increased demand for ethanol can be met by exploration of cheap lignocellulosic feedstock, pretreatment and elimination of fermentation inhibitors using SSF process.

Hence, the present study was undertaken with the objective to provide SSF technology for the efficient conversion of bamboo into ethanol in order to meet out the growing energy demand and its production cost. The biomass is subjected to acid and alkali treatment and the compositional and structural analysis of the pretreated biomass will be carried out. To perform the SSF process, cellulolytic enzymes and isolated native thermotolerant yeast will be used and final hydro lysate is evaluated for ethanol production efficiency to indicate the potential of this feedstock for ethanol production.

\section{Materials and Methods}

\section{Materials}

The bamboo biomass was obtained from the Farmers field in Appakudal, Bhavani, Erode, 
Tamil Nadu, India - 638315. The moisture content was reduced drastically by introducing the substrates to the interior of the Tunnel drier until it reaches the brittle texture. After attaining a brittle texture, the substrate was cut into about $10 \mathrm{~cm}$ length and pulverized by using the Willey mill (M/s. Khera, India). After accomplishing a disintegrated biomass, the substrate was sieved to different micron sizes using sieve shaker (M/s. Jayanth, India) (Plate 1). The physio-chemical characteristics of the substrate such ascellulose, hemicellulose, lignin, reducing sugars, moisture and ash content were analysed using the standard NREL protocol.

\section{Pretreatment of the substrate}

Five grams of the sieved $<250 \mu$ size bamboo substrate was taken in a $250 \mathrm{ml}$ conical flasks and $100 \mathrm{ml}$ of $3 \%$ of concentrated $\mathrm{H}_{2} \mathrm{SO}_{4}$ was added to the flask and incubate for 3 hours to hydrolyze the substrate and the flask was kept for autoclaving at $121^{\circ} \mathrm{C}$ for $30 \mathrm{~min}$ followed by sudden depressurization by fully opening the steam exhaust valve of autoclave. The flasks were cooled to the room temperature $\left(28^{\circ} \mathrm{C}\right)$ and the hydrolyzate was filtered through the Whatman No.1 filter paper. The liquid sample was collected and the reducing sugar content was estimated by DNSA $\operatorname{method}^{7}$.The structural characterization of pretreated substrate and native substrate was carried out using the Scanning Electron Microscope (M/s. FEI Quanta, Netherlands) operated at $2500 \mathrm{KV}$ accelerated voltage. Specimens were prepared for SEM inspection by sticking sample on carbon glue ${ }^{8}$. To investigate and quantify chemical changes in pretreated and untreated lignocellulosic substrates, a spectrum one Fourier Tandom Infra-Red spectroscopy (FTIR) (M/s. Shimadzu, India) was used. All solid samples were dried at $40^{\circ} \mathrm{C}$ for 3 days. The untreated and the pretreated substrates for FTIR analysis were formed into a disc with $\mathrm{KBr}$. The discs used in this work were thin enough to obey the Beer-Lambert Law. Infrared spectra were obtained using a Varian FTIR320 spectrometer (M/s. Varian Technologies, Taiwan) with a resolution of $1 \mathrm{~cm}^{-1}$ in the range of 400 and $4000 \mathrm{~cm}^{-19}$

\section{Organism}

The organism used in the study is elite thermotolerant yeast TY16 Kluyveromyces marxianus (Plate 2) isolated from spent wash storage site in Sakthi distilleries, Erode. The stock culture was maintained in YPD agar medium.

\section{Simultaneous saccharification and fermentation}

The SSF experiment was performed using the optimized parameters obtained through Response Surface Methodology in a one litre round bottom flask containing $500 \mathrm{ml}$ of fermentation medium having pretreated bamboo substrate concentration of 5\%. From the RSM analysis conducted by Design Expert software version 8.0.7.1., the optimum combinations of commercial cellulase enzyme concentration, $\mathrm{pH}$, temperature and fermentation time for maximum ethanol production using SSF process were of $30 \mathrm{FPU}$ $\mathrm{g}^{-1}$ substrate, $5,42.5^{\circ} \mathrm{C}$ and $108 \mathrm{~h}$ respectively (Table 1). The medium was supplemented with ammonium dihydrogen orthophosphate $0.5 \mathrm{~g} \mathrm{l}^{-1}$ and magnesium sulphate $0.025 \mathrm{~g} \mathrm{l}^{-1}$ respectively. The $\mathrm{pH}$ was adjusted to 5.0 with $1 \mathrm{~N} \mathrm{NaOH}$ solution. Then the medium was sterilized at $121^{\circ} \mathrm{C}$ for $15 \mathrm{~min}$ and allowed for cooling. Then, the medium was supplemented with optimized cellulase enzyme concentration of $30 \mathrm{FPU} \mathrm{g}^{-1}$ substrate $(\mathrm{M} / \mathrm{s}$. Novozymes, India). The enzymatic hydrolysis was carried out at $50^{\circ} \mathrm{C}$ for $2 \mathrm{~h}$ to achieve presaccharification before addition of yeast inoculum. Thereafter, the temperature was reduced to $42.5^{\circ} \mathrm{C}$ and the inoculum (10\%) at 
the cell concentration of $5 \times 10^{9} \mathrm{CFU} \mathrm{ml}{ }^{-1}$ was added and incubated until the optimized fermentation time of $108 \mathrm{~h}$. Samples were taken at $0,24,48,72,96$ and $108 \mathrm{~h}$ for analysis of ethanol and reducing sugars. The amount of reducing sugars present was estimated by DNSA method and ethanol by chemical oxidation method ${ }^{10}$.The final ethanol concentration was detected qualitatively using the High Performance Liquid Chromatography (M/s. Agilent Technologies, USA).

\section{Results and Discussion}

The physio-chemical properties of the substrate bamboo was analyzed and found to contain maximum cellulose content of $49.30 \%, 21.20 \%$ of Hemicellulose, $22.10 \%$ of lignin and $1.54 \%$ of Ash respectively (Table 2). The holocellulose content was about 70.5 $\%$ which showed that this substrate has more efficiency to produce more amount of ethanol.

\section{Structural changes in the pretreated and untreated substrate}

Preliminary pretreatment analysis was done with different concentrations of Sulphuric acid and found that at $3 \% \mathrm{H}_{2} \mathrm{SO}_{4}$ at $2 \mathrm{~h}$ incubation time, the reducing sugar released was high when compared with other concentrations. Hence the bamboo was treated with $3 \%$ $\mathrm{H}_{2} \mathrm{SO}_{4}$ at $2 \mathrm{~h}$ incubation time and analyzed for the structural changes using FTIR spectrum. The functional groups of untreated and pretreated bamboo were shown in the FTIR spectra presented in Figure 1. For treated bamboo, there was a strong broad $\mathrm{O}-\mathrm{H}$ stretching vibration of $\alpha$-cellulose at 3425 $\mathrm{cm}^{-1}$. The transmittance at $2854.09 \mathrm{~cm}^{-1}$ and $2376.30 \mathrm{~cm}^{-1}$ was a prominent $\mathrm{C}-\mathrm{H}$ stretching of lignocellulosic complex. The band at $1458.18 \mathrm{~cm}^{-1}$ corresponds to the aliphatic part of lignin and aromatic skeleton vibration, ring breathing in the $\mathrm{C}-\mathrm{O}$ stretching in lignin. The broad band at $1103.28 \mathrm{~cm}^{-1}$ is attributed to stretching to absorption by C-O stretching in lignin, cellulose and hemicellulose. The transmittance at $1064.71 \mathrm{~cm}^{-1}$ was $\mathrm{C}-\mathrm{OH}$ stretching of cellulose and hemicellulose. The band at 802.39 was due to glucosidic linkage. These chemical group of $\mathrm{H}_{2} \mathrm{SO}_{4}$ treated bamboo was absent in untreated bamboo.

SEM images for untreated and $\mathrm{H}_{2} \mathrm{SO}_{4}$ pretreated bamboo substrate was studied. In case of untreated substrate (Plate 3), there was no disturbance in the biomass network which was strongly bonded. The SEM images of $\mathrm{H}_{2} \mathrm{SO}_{4}$ pretreated bamboo showed in Plate 4 revealed formation of small holes on the biomass surface and disruption of the biomass network consistent with hemicelluloses and lignin removal. This showed that acid treatment reduced the fibre length and removed most of the lignin.

\section{SSF process for ethanol production}

The optimum conditions obtained in the RSM were applied in the SSF experiments. In the first step, the selected lignocellulosic substrates of $250 \mu$ particle size bamboo were pretreated with $3 \% \mathrm{H}_{2} \mathrm{SO}_{4}$ for $2 \mathrm{~h}$. After prehydrolysis, commercial cellulase enzyme, $\mathrm{pH}$, temperature and fermentation time were maintained as per the SSF optimized data. Simultaneously saccharification and fermentation was carried out. Ethanol production at different fermentation time intervals was studied. The ethanol production was increased with increase in fermentation time and the maximum ethanol production was occurred at $108 \mathrm{~h}$ whereas the level of reducing sugars was found to be decreased (Table 3). The ethanol concentration of 26.04 $\mathrm{gl}^{-1}$ was produced in bamboo at $108 \mathrm{~h}$. During $108 \mathrm{~h}$ of fermentation time, the maximum amount of reducing sugars was utilized and $0.015 \mathrm{~g} \mathrm{~g}^{-1}$ substrate of reducing sugars from bamboo remained as unutilized. 
The fast growth and adaptability toward various soil and climate conditions make the bamboo a good candidate for a renewable resource and the carbohydrate content was also higher in bamboo ${ }^{11}$

The FTIR analysis of structural changes in the $\mathrm{H}_{2} \mathrm{SO}_{4}$ pretreated and untreated bamboo showed the difference in chemical group. The number of more chemical groups on the pretreated substrate surface was more than that of untreated substrate confirms the removal of hemicelluloses. Hemicellulose is known to coat the cellulose microfibrils in the plant cell wall, forming a physical barrier to access by hydrolytic enzymes. Removal of hemicelluloses from the microfibrils is believed to expose the cellulose surface and to increase the enzymatic hydrolysis of cellulose. Similar findings have been reported by Liu and $\mathrm{Fei}^{12}$ who worked on chemical pretreatment of moso bamboo.

Table.1 Optimum parameters employed for maximum ethanol production from bamboo as predicted by RSM model

\begin{tabular}{|c|c|c|c|c|}
\hline \multirow{2}{*}{$\begin{array}{c}\text { Dependent } \\
\text { variable }\end{array}$} & \multicolumn{4}{|c|}{ Independent variables } \\
\cline { 2 - 5 } & $\begin{array}{c}\text { Cellulase Enzyme } \\
\text { concentration } \\
(\text { FPU })\end{array}$ & $\mathrm{pH}$ & $\begin{array}{c}\text { Temperature } \\
\left({ }^{\circ} \mathrm{C}\right)\end{array}$ & $\begin{array}{c}\text { Fermentation } \\
\text { time }(\mathrm{h})\end{array}$ \\
\cline { 2 - 5 } & 30 & 5 & 42.5 & 108 \\
\hline
\end{tabular}

Table.2 Physio - chemical characterization of lignocellulosic substrate bamboo

\begin{tabular}{|l|c|}
\hline \multicolumn{1}{|c|}{ Properties } & Bamboo \\
\hline Cellulose (\%) & $49.30 \pm \mathbf{0 . 5 6 9}$ \\
\hline Hemicellulose (\%) & $\mathbf{2 1 . 2 0} \pm \mathbf{0 . 2 4 5}$ \\
\hline Lignin (\%) & $22.10 \pm 0.255$ \\
\hline Ash $(\%)$ & $1.54 \pm \mathbf{0 . 0 1 8}$ \\
\hline Moisture (\%) & $\mathbf{1 6 . 7 0} \pm \mathbf{0 . 1 9 3}$ \\
\hline
\end{tabular}

Values in each column represent means of triplicate determinations $\pm \mathrm{SE}$

Table.3 Ethanol and reducing sugar content from bamboo by SSF process

\begin{tabular}{|c|c|c|c|c|c|}
\hline & \multicolumn{5}{|c|}{ Bamboo } \\
\cline { 2 - 6 } & \multicolumn{5}{|c|}{ Time (h) } \\
\cline { 2 - 6 } & $\mathbf{2 4}$ & $\mathbf{4 8}$ & $\mathbf{7 2}$ & $\mathbf{9 6}$ & $\mathbf{1 0 8}$ \\
\hline $\begin{array}{c}\text { Ethanol production } \\
\left(\mathbf{g ~ l}^{-1}\right)\end{array}$ & $5.70 \pm 0.066$ & $11.00 \pm 0.127$ & $18.40 \pm 0.212$ & $21.81 \pm 0.252$ & $26.04 \pm 0.197$ \\
\hline $\begin{array}{c}\text { Reducing sugars } \\
\left(\mathbf{g ~ g}^{-1} \text { of substrate) }\right.\end{array}$ & $0.694 \pm 0.014$ & $0.401 \pm 0.008$ & $0.192 \pm 0.004$ & $0.098 \pm 0.002$ & $0.015 \pm 0.003$ \\
\hline
\end{tabular}

$\mathrm{SSF}$ at $30 \mathrm{FPU} \mathrm{g}^{-1}$ of substrate, $\mathrm{pH} 5,42.5^{\circ} \mathrm{C}, 108 \mathrm{~h}$

$\mathrm{S}$ - Substrate

I - Incubation time

S x I - Substrate x Incubation time

Values in each column represent means of triplicate determinations \pm SE 
Plate.1 Bamboo substrate used for SSF process

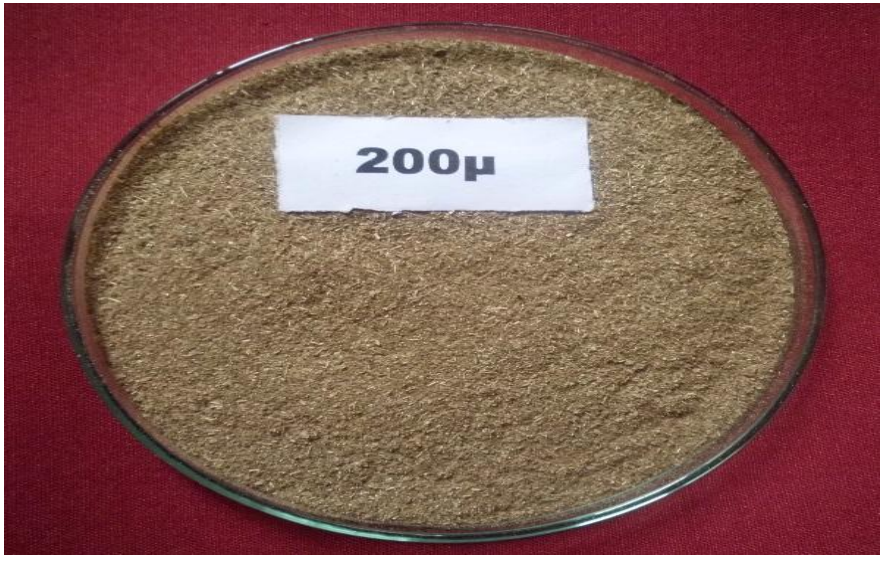

Plate.2 Microphotographs of thermotolerant yeast isolate TY 16
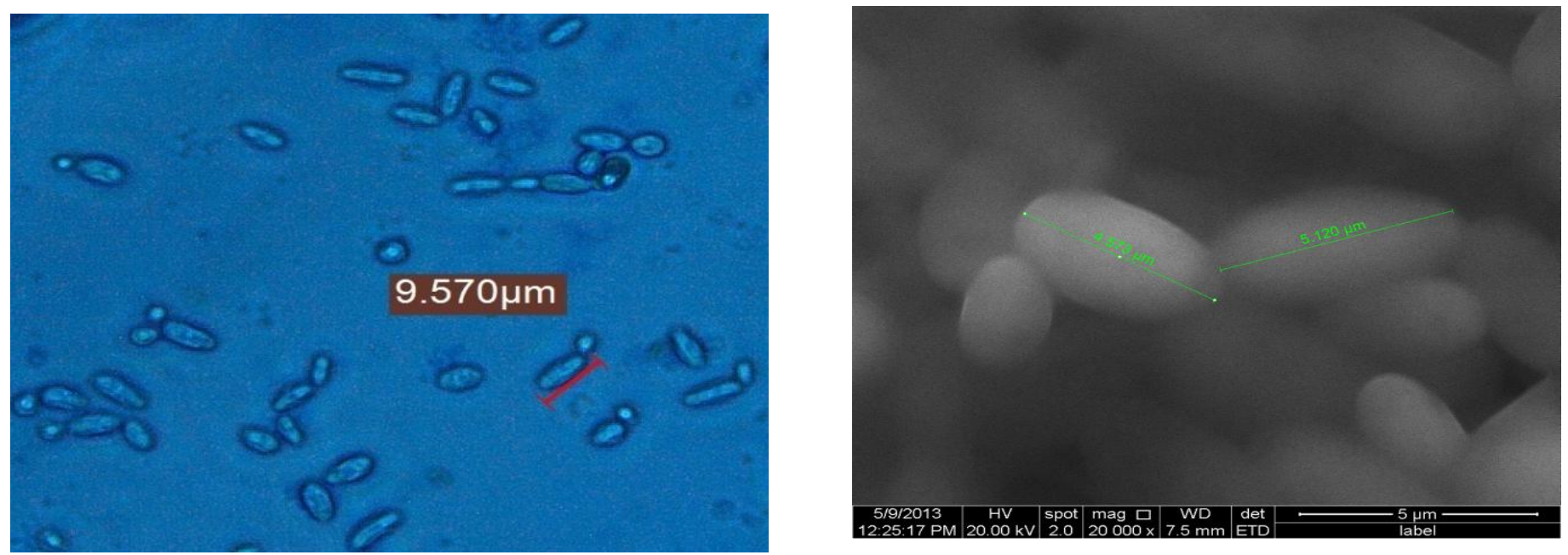

Plate.3 SEM Microphotographs of untreated bamboo at different magnifications
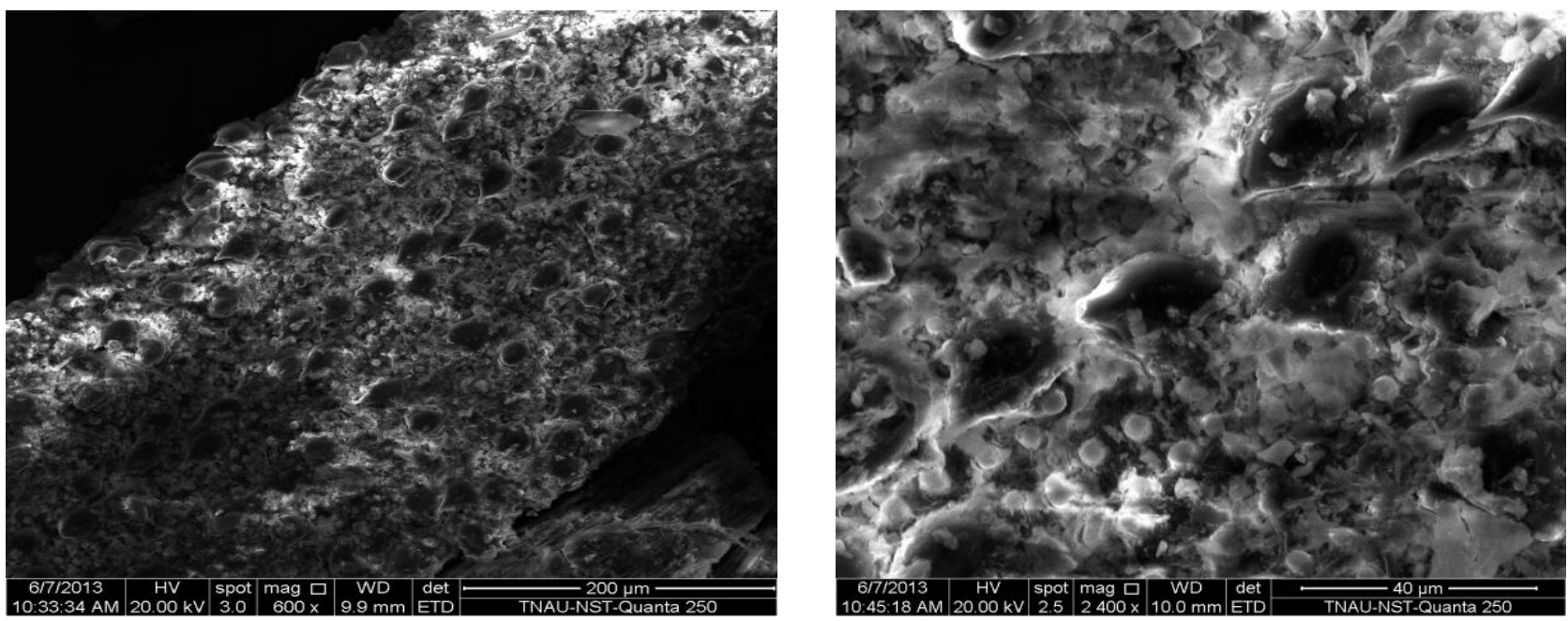
Plate.4 SEM Microphotographs of $\mathrm{H}_{2} \mathrm{SO}_{4}$ treated bamboo at different magnifications
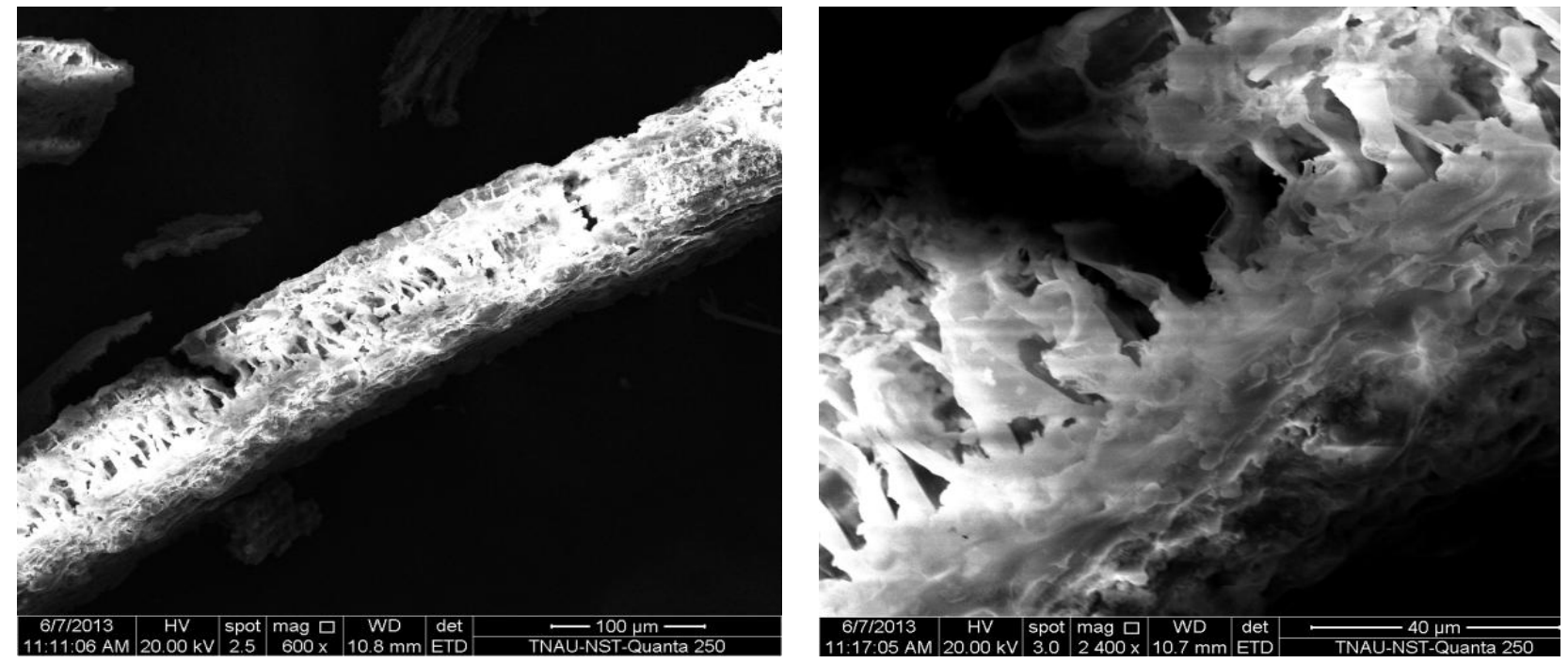

Fig. 1. FTIR analysis of chemical changes in bamboo treated with $\mathrm{H}_{2} \mathrm{SO}_{4}$ and untreated

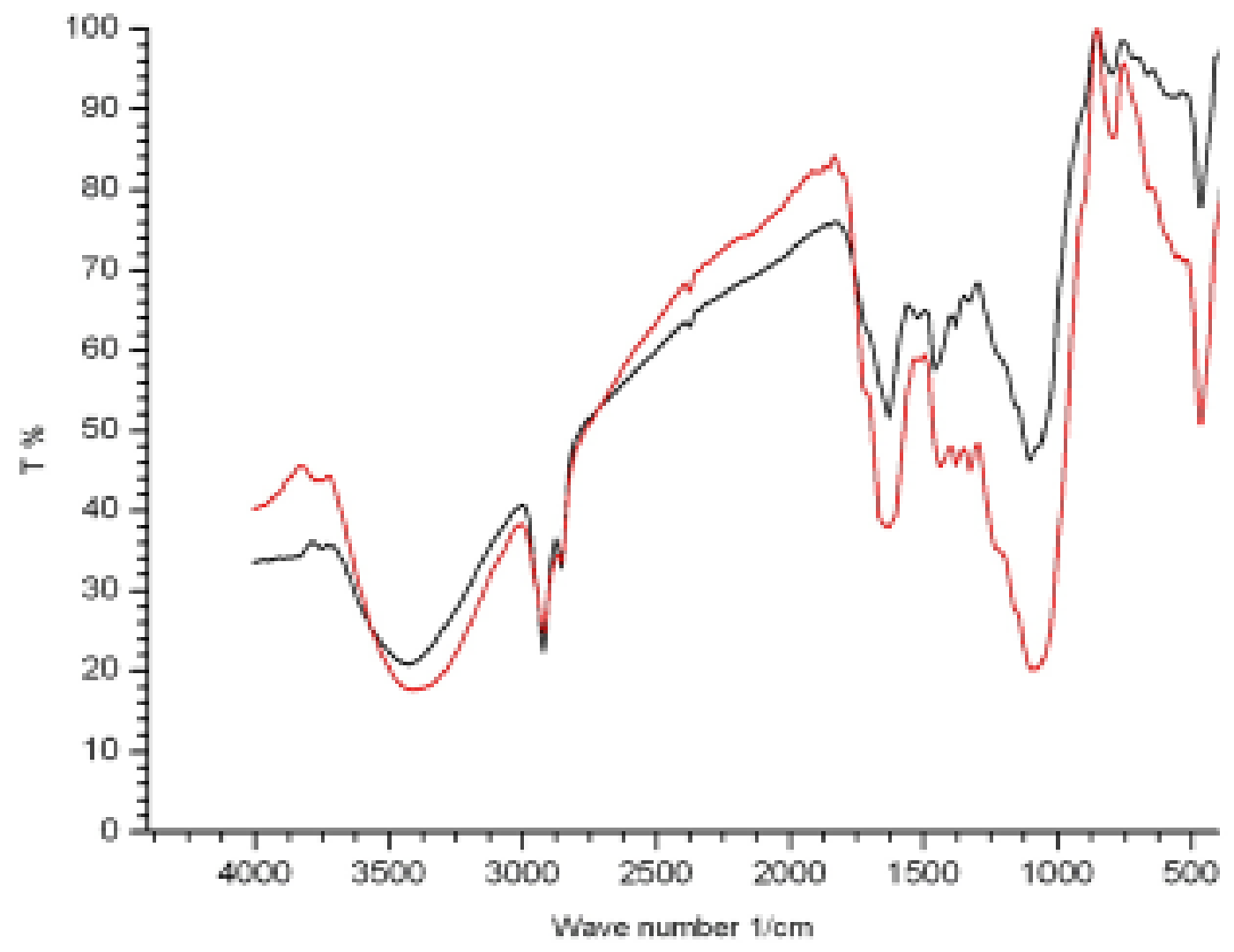

— Bambog treated and —_ Bamboo untreated 
Flowchart for production of bioethanol from bamboo substrate

Bamboo Substrate - Dried to brittle texture-pulversied and sieved to different sizes

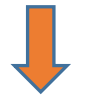

Physio chemical composition analysis using NREL procedure

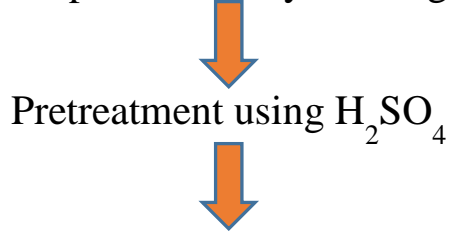

Structural characterization of treated and untreated substrate using SEM and FTIR

SSF process using RSM optimized parameters

(5\% substrate conc, Cellulase enzyme - $30 \mathrm{FPU} / \mathrm{g}$ of substrate

Temp $-42.5^{0} \mathrm{C}, \mathrm{pH}-5$, Fermentation time $-108 \mathrm{~h}$ )

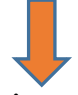

Presaccharification at $50^{\circ} \mathrm{C}$ for $2 \mathrm{~h}$

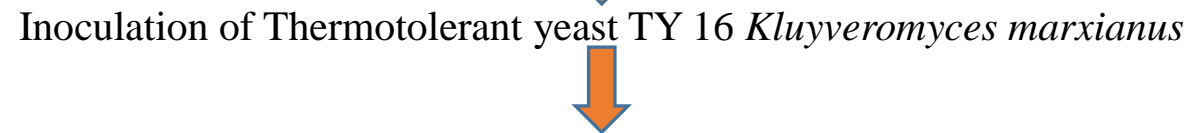

Reducing sugar and ethanol concentration analysis at different time interval

The Scanning electron microscopic images of $\mathrm{H}_{2} \mathrm{SO}_{4}$ pretreated substrate revealed that acid treatment effectively disrupts microfibrils. This showed that the accessibility of enzyme to the cellulose was increased by the acid pretreatment. Some lignin droplets appeared to be present on the surface of treated substrates suggested that some lignin melted during $\mathrm{H}_{2} \mathrm{SO}_{4}$ and agglomerated on the surface. These results were consistent with reports by Chundawat et al., ${ }^{13}$ that carbon rich components (lignin) were found on the surface after pretreatment. Kumar et al., ${ }^{14}$ also reported that small holes on the biomass surface disrupt the biomass network consistent with hemicelluloses and lignin removal during pretreatment. The simultaneous saccharification and fermentation (SSF) process was a favored option for conversion of the lignocellulosic biomass into ethanol because it provides enhanced rates, yields, and concentrations of ethanol with less capital investment compared to competing processes. In this study, ethanol production from bamboo lignocellulosic substrate was carried out as per the optimized variables of the SSF process. The ethanol production and utilization of reducing sugars were recorded over fermentation time. The ethanol concentration increased when the fermentation time increased and the reducing sugars get decreased. This was because at the initial stage, the yeast cells utilized reducing sugars for their growth to enter into the logarithmic phase. Once cells attained maximum growth, it started conversion of 
reducing sugars to ethanol and produced maximum production of ethanol at $108 \mathrm{~h}$. The use of thermotolerant yeast also leads to production of more ethanol at high temperature of $42.5^{\circ} \mathrm{C}$. The presence of reducing sugars in the fermentation medium at the last stage of SSF experiments indicated continuation of cellulase activity whereas yeast fermentation had finished. Yeast performance may be affected both by very low glucose concentration resulting in metabolic stress conditions and ethanol presence in fermenting medium. The feasibility of using $10 \% \quad(\mathrm{w} / \mathrm{v})$ substrate concentration in SSF with Kluyveromyces marxianus was considered to be relevant, since earlier studies on this process have reported the limiting effect of elevated substrate concentrations due to difficulties in stirring the material or high ethanol inhibiting concentration.

Based on the experimental results of this study and with the above advantages in mind, it is suggested that the simultaneous saccharification and conversion of bamboo substrate to ethanol at $42^{\circ} \mathrm{C}$ in the presence of exogenously added cellulases and thermotolerant ethanol-producing yeast represents a novel system for use. Acid pretreatment of materials tested is shown to be an efficient way to enhance process yields. Nevertheless, it is assumed that yields obtained are all relatively low for industrial ethanol production processes and that further improvements in terms of increased ethanol yields, are necessary to achieve an economical process.

From the study, it was concluded that bamboo has the potential to use as substrate for bio ethanol production. The results showed that ethanol production using SSF process was found to be one of the useful method to achieve the maximum conversion of lignocellulosic substrate to bio ethanol.

\section{References}

1 Sathitsuksanoh N, Zhu Z G, Ho T J, Bai $\mathrm{M}$ D and Zhang $\mathrm{Y} H \mathrm{P}$, Bamboo saccharification through cellulose solvent-based biomass pretreatment followed by enzymatic hydrolysis at ultra-low cellulase loadings, Bioresour Technol, 101 (2010) 4926 - 4929.

2 Li Z, Jiang Z, Fei B, Liu X and Yu Y, Bioconversion of Bamboo to bioethanol using the two stage organosolv and alkali treatment, BioResources, 7(4) (2012a) 5691-5699.

3 Li Z, Jiang Z, Fei B, Pan X, Cai Z, Liu $\mathrm{X} \& \mathrm{Yu} \mathrm{Y}$, Ethanol organosolv pretreatment of bamboo for efficient enzymatic saccharification, BioResources, 7(3) (2012b) 3452 - 3462

4 Ohgren K, Bura R, Lesnicki G, Saddler J \&Zacchi G, A comparison between simultaneous saccharification and fermentation and separate hydrolysis and fermentation using steam pretreated corn stover, Process Biochem, 42 (2007) 834 - 839.

5 Krishna H S, Reddy T J and Chowdary $\mathrm{G} \mathrm{V}$, Simultaneous saccharification and fermentation of lignocellulosic wastes to ethanol using a thermotolerant yeast, Bioresour Technol, 77 (2001) 193 - 196

6 Ballesteros M, Oliva J M, Negro M J, Manzanares P and Ballesteros I, Ethanol from lignocellulosic materials by a simultaneous saccharification and fermentation process (SSF) with Kluyveromyces marxianus CECT 10875, Process Biochem, 39 (2004) 1843 - 1848.

7 Miller G L, Use of dinitrosalicyclic acid reagent for determination of reducing sugars, Anal Chem, 31 (1959): 426 428.

$8 \mathrm{Yu}$ J, Xuzhang D and Tan T, Ethanol production by solid state fermentation of sweet sorghum using thermotolerant 
yeast strain. Fuel Process Technol, 89 (2008): 1056 - 1059.

9 Guo, G., W. Chen, W. Chen, L. Men and W. Hwang. 2008. Characterization of dilute acid pretreatment of silvergrass for ethanol production. Bioresour Technol, 99: 6046 - 6053.

10 Caputi, A., J. M. Veda and T. Brown. 1968. Spectrophotometric determination of chromic complex formed during oxidation of alcohol. Am $\mathrm{J}$ Enol Viticult, 19: 160-165.

11 Sun, Z.Y., Y.Q. Tang, T. Iwanaga, T. Sho and K. Kida. 2011. Production of fuel ethanol from bamboo by concentrated sulfuric acid hydrolysis followed by continuous ethanol fermentation. Bioresour Technol, 102: 10929-10935.
12 Liu, Z. and B. Fei. 2013. Characteristics of Moso Bamboo with Chemical Pretreatment. In: Sustainable Degradation of Lignocellulosic Biomass - Techniques, Applications and Commercialization. http://dx.doi.org/10. 5772/55379. Pp. 1-12.

13 Chundawat, S.P., B. Venkatesh and B.E. Dale. 2007. Effect of particle size based separation of milled corn stover on AFEX pretreatment and enzymatic digestibility. Biotechnol Bioeng, 96(2): 219-231.

14 Kumar, P., D.M. Barrett, M.J.Delwiche and P. Stroeve. 2009. Methods for pretreatment of lignocellulosic biomass for efficient hydrolysis and biofuel production. Ind Eng Chem Res, 48: 3713-3729.

\section{How to cite this article:}

Sasikala Ganesan and Gopal, N.O. 2019. Production of Bioethanol from Bamboo using Thermotolerant Yeast with Simultaneous Saccharification and Fermentation Process. Int.J.Curr.Microbiol.App.Sci. 8(03): 1718-1727. doi: https://doi.org/10.20546/ijcmas.2019.803.200 